\title{
Wave influence on polar mesosphere summer echoes above Wasa: experimental and model studies
}

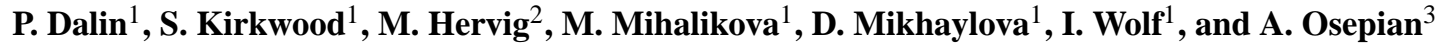 \\ ${ }^{1}$ Swedish Institute of Space Physics, Box 812, 98128 Kiruna, Sweden \\ ${ }^{2}$ GATS Inc., Driggs, ID 83422, USA \\ ${ }^{3}$ Polar Geophysical Institute, Halturina 15, 183023 Murmansk, Russia \\ Correspondence to: P. Dalin (pdalin@irf.se)
}

Received: 25 January 2012 - Revised: 29 April 2012 - Accepted: 2 July 2012 - Published: 13 August 2012

\begin{abstract}
Comprehensive analysis of the wave activity in the Antarctic summer mesopause is performed using polar mesospheric summer echoes (PMSE) measurements for December 2010-January 2011. The 2-day planetary wave is a statistically significant periodic oscillation in the power spectrum density of PMSE power. The strongest periodic oscillation in the power spectrum belongs to the diurnal solar tide; the semi-diurnal solar tide is found to be a highly significant harmonic oscillation as well. The inertial-gravity waves are extensively studied by means of PMSE power and wind components. The strongest gravity waves are observed at periods of about $1,1.4,2.5$ and $4 \mathrm{~h}$, with characteristic horizontal wavelengths of $28,36,157$ and $252 \mathrm{~km}$, respectively. The gravity waves propagate approximately in the west-east direction over Wasa (Antarctica). A detailed comparison between theoretical and experimental volume reflectivity of PMSE, measured at Wasa, is made. It is demonstrated that a new expression for PMSE reflectivity derived by Varney et al. (2011) is able to adequately describe PMSE profiles both in the magnitude and in height variations. The best agreement, within $30 \%$, is achieved when mean values of neutral atmospheric parameters are utilized. The largest contribution to the formation and variability of the PMSE layer is explained by the ice number density and its height gradient, followed by waveinduced perturbations in buoyancy period and the turbulent energy dissipation rate.
\end{abstract}

Keywords. Atmospheric composition and structure (Middle atmosphere - composition and chemistry)

\section{Introduction}

In the polar summer mesopause around $80-90 \mathrm{~km}$ altitude, strong radar returns are often seen in VHF radar measurements, which are called Polar Mesosphere Summer Echoes (PMSE). They are caused by a combination of a turbulent medium and plasma processes, in which electricallycharged small aerosols (of several $\mathrm{nm}$ in diameter) play a dominating role (Cho and Röttger, 1997; Rapp and Lübken, 2003). PMSE appear in the same season and at similar altitudes as noctilucent clouds (NLC) and they are closelyrelated phenomena, the latter being composed of larger neutral ice particles of a few tens of $\mathrm{nm}$ in diameter and lying in the lowermost part of a PMSE layer (Nussbaumer et al., 1996; von Zahn and Bremer, 1999). Polar mesospheric clouds (PMC) are observed from space and are nearly the same phenomenon as NLC. Hervig et al. (2011) have shown a similar result that the peak PMSE altitude is about $2 \mathrm{~km}$ higher than the altitude of the ice mass density peak.

PMSE and NLC are wonderful natural laboratories for studying the highly dynamical regime of the summer mesopause, in which turbulent vortices as well as waves of different scales from a few $\mathrm{km}$ to several thousand $\mathrm{km}$ regularly occur (Kirkwood and Réchou, 1998; Dalin et al., 2004; Klekociuk et al., 2008; Morris et al., 2009; Pautet et al., 2011). PMSE are extensively exploited to verify the existing theories on the dusty plasma-neutral turbulent state of the mesosphere (Kelley et al., 1987; Cho and Röttger, 1997; Rapp and Lübken, 2003; Rapp et al., 2008; Varney et al., 2011). Low temperatures are needed to form ice aerosols while the turbulence and energetic precipitating particles from the magnetosphere are also important products 
for PMSE formation. In particular, when considering effects from different contributors to PMSE variability, it is important to separate strong ionization effects due to energetic particle precipitation from others players. In particular, PMSE and NLC have different daily variations: the former are observed to be strongest around noon and weakest in the evening hours, whereas the latter have a maximum in the morning hours and a minimum around noon (Nilsson et al., 2008; Smirnova et al., 2010; Fiedler et al., 2005). Thus, it is likely that PMSE have a strong variation component due to a highly variable ionization constituent. That is why it is important to separate the energetic particle component from the local-time variations of PMSE to estimate a "pure" effect of the diurnal component of the ice particle variability (Kirkwood et al., 2010a). In turn, slow modulation in local time of ice particles might be responsible for a long-term increase seen in polar mesospheric clouds observed by satellite (Shettle et al., 2009). On the other hand, Smirnova et al. (2010) have demonstrated no statistically significant trends in PMSE occurrence rate and length of PMSE season over the period of 1997-2008 in northern Sweden. The issue concerning long-term trends in the properties of ice particles in the polar summer mesopause requires additional comprehensive studies.

In this sense, the MST radar MARA (Moveable Atmospheric Radar for Antarctica) is probably the best tool since it is located in Antarctica at Wasa station (geographic coordinates: $73.05^{\circ} \mathrm{S}, 13.4^{\circ} \mathrm{W}$, geomagnetic latitude is $61^{\circ}$ ) with a maximum separating distance from the auroral zone (compared to other radars), thus allowing studies of PMSE variability without complicated effects of energetic particle precipitation.

In this paper we use PMSE data obtained with MARA. The present study is done in two directions. Firstly, PMSE variability for the austral summer season of December 2010 January 2011 is investigated in order to get information on dominating dynamical processes in the Antarctic summer mesopause. In the second part, case studies on comparison between model and experimental PMSE reflectivity, measured in the austral summer of 2008 , are considered with the aim to investigate the relative importance of the number density of ice particles and wave perturbations in PMSE reflectivity.

\section{Data source}

MARA is Moveable Atmospheric Radar for Antarctica, which is a $54.5 \mathrm{MHz}$ wind-profiler radar. MARA was operating during austral summer campaigns at the Wasa Swedish station $\left(73^{\circ} 03^{\prime} \mathrm{S}, 13^{\circ} 25^{\prime} \mathrm{W}\right)$ for $2007-2011$. MARA is planned to operate at the Troll Norwegian station from November 2011 on a year-round operation basis. MARA is designed to be easily set up and disassembled with minimal impact on the ground and environment. The calibra-

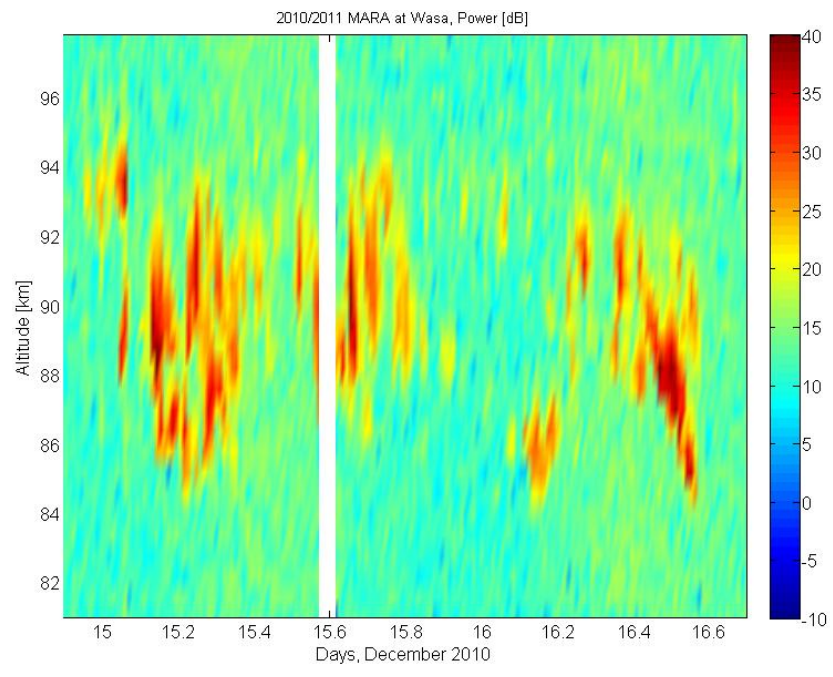

Fig. 1. En example of PMSE power data in the height-time domain in December 2010.

tion of MARA was made using the galactic noise level. Before shipping to Antarctica, MARA was in operation in Kiruna (Sweden) during late summer 2006 in order to make an accurate cross-calibration with the similar MST radar ESRAD. A detailed description of MARA, calibration and cross-calibration procedure as well as the measurement technique can be found in Kirkwood et al. (2007).

\section{Analysis of wave activity above Wasa in the 2010-2011 summer season}

In the present section, we want to estimate gravity wave characteristics which are typical for the Antarctic summer mesopause based on the PMSE power signal and information on the wind. Radar measurements with height resolution of $600 \mathrm{~m}$ and temporal resolution of $1 \mathrm{~min}$ were obtained at Wasa from 14 December 2010 to 12 January 2011. The 2010-2011 period was chosen as a test period for the harmonic analysis since it has a small number of interruptions in the recorded time series (which is of importance for a harmonic analysis), and also, it has a medium length of recorded data sets compared to other four seasons; that is the 20102011 period is a characteristic period of PMSE observations over Wasa which obeys the requirements of the Fourier analysis. In the present study, we use data averaged for $15 \mathrm{~min}$ to filter out noise variations at high frequencies. PMSE are very often modulated by wave propagation both in the vertical direction and in the time domain, and can be seen in typical plots (Fig. 1). Sometimes one can see double layers, which presumably are built by upward propagating gravity waves.

Two-dimensional filtering analysis more clearly reveals modulation of PMSE layers. Figure 2 illustrates downward progressing wave disturbances with observed periods of about $4 \mathrm{~h}$ and vertical wavelengths of $4-6 \mathrm{~km}$. A 4-pole 


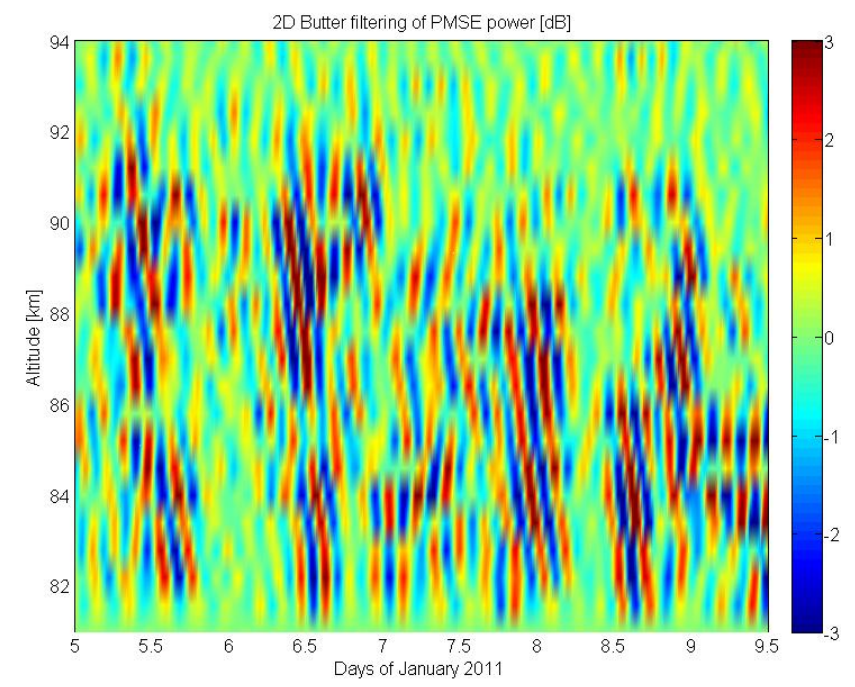

Fig. 2. An example of gravity wave patterns presented in the PMSE power data. A 2-D filtering procedure was applied to the data.

bi-directional Butterworth filter (both in space and time) was applied to the PMSE power data. The Butterworth filter has been constructed to extract waves with periods of $2-7 \mathrm{~h}$ and vertical wavelengths of $1300-7000 \mathrm{~m}$. A bi-directional filter ensures that no phase changes are induced by the filtering algorithm.

Now we aim to identify typical periodicities observed around the high-latitude mesopause during the 2010/2011 Antarctic summer. To make it clear what periods and vertical wavelengths of gravity waves are more significant, the most advanced multiple-taper method (MTM) has been used to estimate the power spectral density (PSD) of the variations in original data (Percival and Walden, 1993). This method uses linear or nonlinear combinations of modified periodograms in order to minimize spectral leakage outside of the analyzed spectral band. Spectra of the PMSE power have been considered both in the time and space domain. To estimate the significance of extracted harmonics the red noise and its $95 \%$ level of significance has been found in the PSDs. Spectral peaks which are above the $95 \%$ confidence level should be regarded as significant harmonic oscillations in a time series. A detailed description of the application of the MTM to geophysical data and of the red noise procedure can be found in Mann and Lees (1996).

Figure 3 demonstrates the PSD of the PMSE power in the time domain, with PMSE data being averaged for the height interval between 85 and $89.5 \mathrm{~km}$ in order to guaranty the presence of periodic variations in almost whole height range of PMSE occurrence. Several significant spectral peaks are clearly seen in the power spectrum: about 1 and $1.4 \mathrm{~h}, 2.5$, 4,12 and $24 \mathrm{~h}$ as well as 2.3 days. Note that we carefully estimated the noise level at $75-80 \mathrm{~km}$ and subtracted it from PMSE power data to ensure that no galactic noise variations are presented in the PMSE time series. The 12 and $24 \mathrm{~h}$ pe-

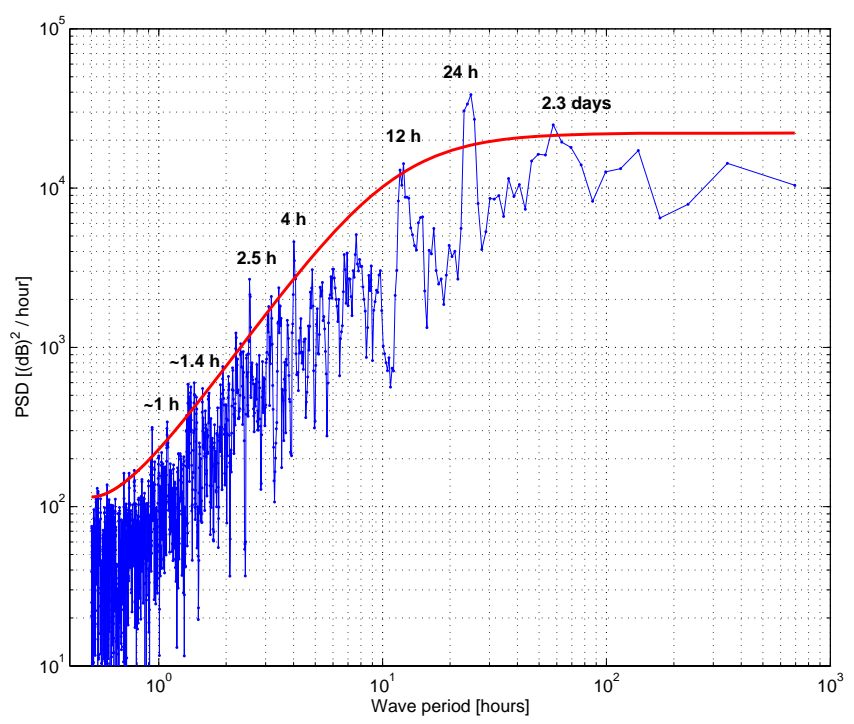

Fig. 3. Power spectral density of the time series of PMSE power averaged for the height range of $85.0-89.5 \mathrm{~km}$. The red curve represents the $95 \%$ confidence level of the red noise. The periods of significant harmonic oscillations are indicated.

riods are well establish in PMSE (Kirkwood and Réchou, 1998) and in the upper atmosphere, and correspond to the semi-diurnal and diurnal solar thermal tides, respectively. The 2.3-day oscillation is due to a westward/eastward propagating quasi 2-day planetary wave, which is also a well established atmospheric periodic process in the upper atmosphere (Muller and Nelson, 1978). Other significant observed periods are caused by upward propagating inertia-gravity waves, which are comprehensively studied below. Also, there is a peak at about $135 \mathrm{~h}$ (5.6 days) in the PSD, which is indication of the presence of a 5-day planetary wave, but this peak lacks statistical significance; this feature is considered in the Discussion.

The fraction of the total PMSE variability due to the statistically significant wave variations can be estimated from the sampled power spectrum density presented in Fig. 3, as comprising about $20 \%$ of the total PMSE variability. Note that PMSE should not equally respond to variations at all periods since oscillations at different periods have different amplitudes.

Figure 4 shows the PSD of PMSE power in the height domain. We have carefully examined the entire data set of the 2010/2011 summer in order to identify the most significant wave disturbances in the height range of PMSE occurrences. Two time intervals on 30 December 2010 and 12 January 2011 have been found, representing significant harmonic oscillations with vertical wavelengths of about $3 \mathrm{~km}$ (upper panel) and of about $6 \mathrm{~km}$ (lower panel). Note that these wavelengths are also present at other times in the course of the 2010/2011 austral summer, but they have less statistical significance at other time intervals. 

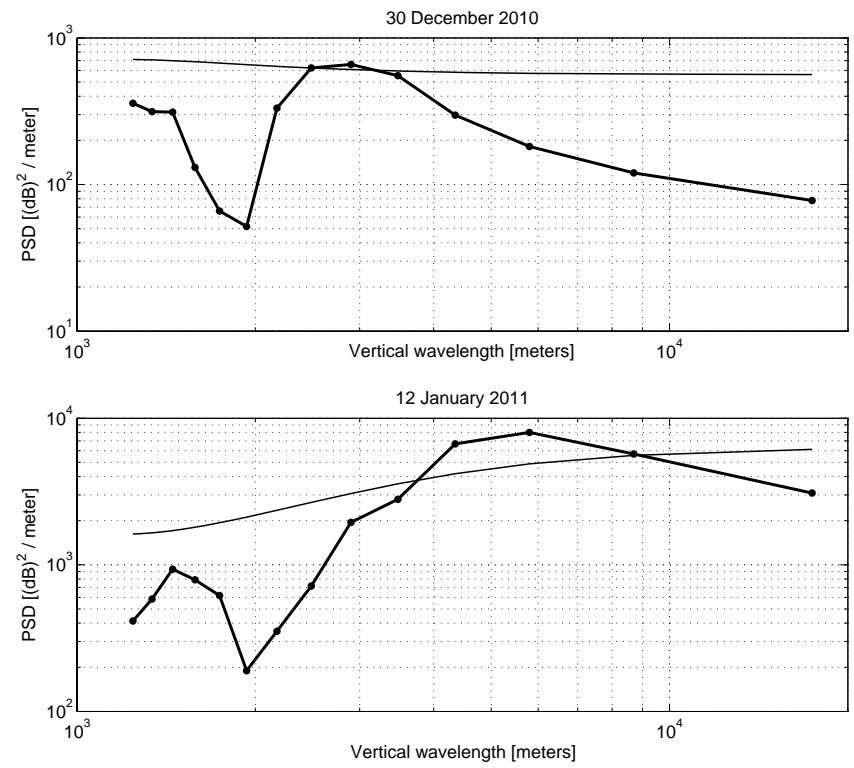

Fig. 4. Power spectrum density of PMSE power in the height domain. The thin line is the $95 \%$ confidence level of the red noise. The upper panel is for 30 December 2010, the lower panel is for 12 January 2011.

Where we have identified statistically significant periodicities in PMSE variability in the time-height domain, it is worth of estimating the whole set of gravity wave parameters for the harmonic oscillation we have found. It is possible to do this by analyzing simultaneous and common volume variations in wind components (zonal, meridional and vertical), which are measured by the spaced antenna technique when the PMSE signal is present.

To quantify gravity wave parameters, we have applied the Stokes parameter spectra technique, which was used in a number of publications (Eckermann and Vincent, 1989; Vincent and Fritts, 1987; Eckermann, 1996; Dalin et al., 2004). The essential point of the technique is that a given vertical profile of zonal and meridional velocity perturbations $(U(z)$ and $V(z))$ is assumed to contain several harmonic oscillations. Fourier transforming them over their full height ranges yields complex components:

$$
U(m)=U_{R}(m)+i U_{I}(m)
$$$$
V(m)=V_{R}(m)+i V_{I}(m)
$$

where $m$ is the vertical wave number. Then, power spectral densities for the standard four Stokes parameters $(I, D, P$, $Q$ ) are defined by the following equations:

$$
\begin{aligned}
& I(m)=A\left(\overline{U_{R}^{2}(m)}+\overline{U_{I}^{2}(m)}+\overline{V_{R}^{2}(m)}+\overline{V_{I}^{2}(m)}\right) \\
& D(m)=A\left(\overline{U_{R}^{2}(m)}+\overline{U_{I}^{2}(m)}-\overline{V_{R}^{2}(m)}-\overline{V_{I}^{2}(m)}\right) \\
& P(m)=2 A\left(\overline{U_{R}(m) V_{R}(m)}+\overline{U_{I}(m) V_{I}(m)}\right) \\
& Q(m)=2 A\left(\overline{U_{R}(m) V_{I}(m)}-\overline{U_{I}(m) V_{R}(m)}\right)
\end{aligned}
$$

where $A$ is a scaling constant, and overbars denote averages over a number of independent spectra, to remove the effects of incoherent motions. The degree of polarization of the wave $d(m)$ is expressed by the equation:

$d^{2}(m)=\frac{D^{2}(m)+P^{2}(m)+Q^{2}(m)}{I^{2}(m)}$

The values of $d(m)$ changes in the range of $0 / 1$. Parameter $d(m)$ is an analog to the cross-spectrum value but the former does not depend on the rotation of the semi-major axis of the wave ellipse and therefore it represents better the wavevariance content. The phase of ellipticity $\Phi(m)$, the orientation of semi-major axes of the ellipse $\Theta(m)$ and axial ratio $R(m)$ are defined by the following equations:

$$
\begin{aligned}
& \Phi(m)=\operatorname{arctg} \frac{Q(m)}{P(m)} \\
& \Theta(m)=\frac{1}{2} \operatorname{arctg} \frac{P(m)}{D(m)} \\
& R(m)=\operatorname{tg}\left(\frac{1}{2} \arcsin \left(\frac{Q(m)}{d(m) \cdot I(m)}\right)\right)
\end{aligned}
$$

The axial ratio of the polarization ellipse and direction of the wave propagation are determined from the Stokes analysis of the wind measurements, as is the vertical wavenumber. The observed frequency $\left(\omega_{0}\right)$ of periodic oscillations is found from the PSD of PMSE power variations. The gravity wave parameters (intrinsic frequency and horizontal wavenumber) can be deduced by solving the equation system of the dispersion relation and Doppler equation, which can be found elsewhere (for example, Cho, 1995). Finally, the horizontal and vertical components of the wave phase velocity are given by the following equations:

$$
\begin{aligned}
& v_{p h}=\hat{\omega} / k \\
& v_{p z}=\hat{\omega} / m
\end{aligned}
$$

where $\hat{\omega}$ is the intrinsic frequency (relative to the ambient air) of the gravity wave, $k$ is the horizontal wavenumber and $m$ is the vertical wavenumber. The horizontal and vertical components of the group velocity of the wave are defined as follows:

$$
\begin{aligned}
& v_{g h}=\partial \hat{\omega} / \partial k \\
& v_{g z}=\partial \hat{\omega} / \partial m
\end{aligned}
$$

Figure 5 shows an example of the Stokes spectral analysis for the case on 30 December 2010. One can see a peak in the degree of polarization at about $3 \mathrm{~km}$ meaning that there was an almost pure harmonic oscillation at this particular wavelength. Note that this vertical wavelength is the same as was found in the spectral analysis of the PMSE power data, confirming the presence of a gravity wave with vertical wavelength equal to $3 \mathrm{~km}$ both in the wind measurements and PMSE power. As the Stokes analysis determines the orientation with a $180^{\circ}$ ambiguity, we choose the direction of the wave propagation with a component against the mean wind; otherwise there is a large probability for a gravity wave 

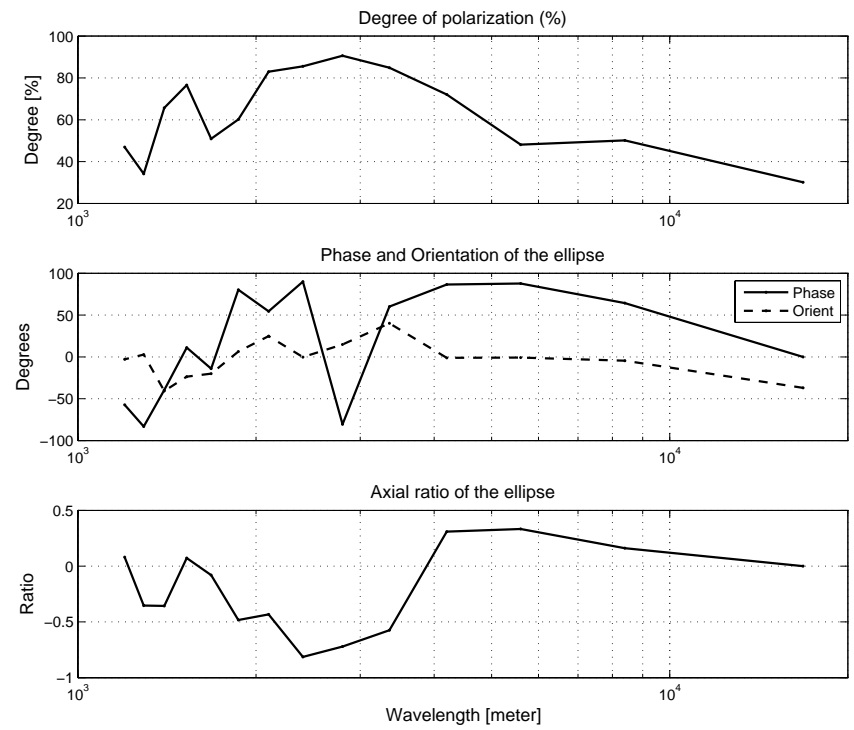

Fig. 5. Stokes spectral parameters of the wind measurements on 30 December 2010.

to meet a critical level at certain height where the wave is destroyed and its energy is distributed into the background wind. The results of gravity wave parameter estimations are presented in Table 1.

From Table 1 it follows that gravity waves prefer to propagate approximately in the west-east direction, with characteristic horizontal wavelengths $\left(L_{\mathrm{h}}\right)$ of 28 and/or $36 \mathrm{~km}$ (middle-scale range) and of 157 and/or $252 \mathrm{~km}$ (large-scale range), with horizontal phase velocities $\left(v_{p h}\right)$ about 9 and $18 \mathrm{~m} \mathrm{~s}^{-1}$ and vertical phase velocities $\left(v_{p z}\right)$ about $-0.7-$ $0.9 \mathrm{~m} \mathrm{~s}^{-1}$ and $-0.4-0.6 \mathrm{~m} \mathrm{~s}^{-1}$, respectively. Note that these parameters are close to and partly within the range of those estimated from an analysis of gravity wave activity above the Scandinavian ridge by the ESRAD VHF radar and the Andenes MF radar, which showed a middle-scale gravity wave of $L_{\mathrm{h}}=41.5 \mathrm{~km}, v_{p h}=6.3 \mathrm{~m} \mathrm{~s}^{-1}, v_{p z}=-0.3 \mathrm{~m} \mathrm{~s}^{-1}$ above Esrange and a large-scale gravity wave of $L_{\mathrm{h}}=$ $169 \mathrm{~km}, v_{p h}=15.6 \mathrm{~m} \mathrm{~s}^{-1}, v_{p z}=-0.51 \mathrm{~m} \mathrm{~s}^{-1}$ above Andenes (Dalin et al., 2004). The Wasa station is located on a small nunatak at $440 \mathrm{~m}$ above sea level and about $200 \mathrm{~m}$ above the surrounding glaciers; in addition, the Vestfjella Mountains (of $500-900 \mathrm{~m}$ height) lie in close proximity, about $40-50 \mathrm{~km}$ southwest of Wasa. The simulations made by Arnault and Kirkwood (2012) have demonstrated that these mountains are capable of generating strong gravity waves, which can propagate up to the lower stratosphere when there is not too much shear in the zonal wind. Thus, it seems that this kind of gravity wave is a common characteristic of the summer mesopause, which could be induced by the orographic source.

In general, the wave-driven periodicities act on PMSE in a similar way as any periodic motion in the atmosphere acts on clouds composed of ice particles. The periodic temperature variations can move the air above and below the frost point temperature, and cold and warm phases of the wave favour growth of ice particles or their sublimation, respectively. The wave-driven variations in wind components with height can also play a significant role since they create an imbalance in the relation between the stability of the air and wind shear, producing variations in the gradient Richardson number, to which the PMSE reflectivity is proportional (see Sect. 4). Finally, there is a general dependence of radar reflectivity on static stability (Hocking, 1985), and this parameter is perturbed by waves.

\section{Modeling of PMSE reflectivity and comparison with experimental data}

PMSE height profiles are utilized in the present study for the austral summer of December 2007/January 2008, a time interval which is characterized by quiet geophysical conditions which minimizes the ionization effects due to precipitating energetic particles. The latter is a challenge to take into account when modeling, and it is a matter of future research. Also, the average relation between PMSE reflectivity and satellite measurements during this period has been studied by Kirkwood et al. (2010a) and we continue to investigate this time interval, looking more at PMSE variability (see below). Experimental values of PMSE reflectivity were calculated based on the algorithm described in detail in Kirkwood et al. (2007).

In the present section, we want to estimate what quantities of the neutral-dusty plasma mesospheric environment influence PMSE variability in relation to a newly derived expression for PMSE reflectivity by Varney et al. (2011), their Eqs. (44)-(46). We reprint these equations since it is important for understanding the mechanism of PMSE formation:

$$
\eta(k)=8 \pi^{3} r_{\mathrm{e}}^{2} \frac{f_{\alpha} q R i}{P r^{\mathrm{t}} \omega_{\mathrm{B}}^{2}} \sqrt{\varepsilon v_{\mathrm{a}}} \bar{S}^{2} \tilde{M}^{2} k^{-3} \exp \left(\frac{-q\left(\eta_{\mathrm{K}} k\right)^{2}}{S c}\right)
$$

$\bar{S} \equiv Z_{\mathrm{d}}\left(\frac{N_{\mathrm{e}}}{N_{\mathrm{e}}+Z_{\mathrm{i}}^{2} N_{\mathrm{i}}}\right)$

$\tilde{M} \equiv\left(\frac{\omega_{\mathrm{B}}^{2} N_{\mathrm{d}}}{g}-\frac{\mathrm{d} N_{\mathrm{d}}}{\mathrm{d} z}-\frac{N_{\mathrm{d}}}{H_{\mathrm{n}}}\right)$

where $\eta$ is PMSE reflectivity, $k$ is the Bragg scattering wavevector, $\omega_{\mathrm{B}}$ is the angular Brunt-Väisälä frequency, $\varepsilon$ is the turbulent energy dissipation rate, $r_{\mathrm{e}}$ is the electron radius, $R i$ is the Richardson number, $\eta_{\mathrm{K}}$ is the Kolmogorov microscale, $v_{\mathrm{a}}$ is the kinematic viscosity of air, $q$ is the Batchelor constant, $f_{\alpha}$ is the proportionality constant, $\operatorname{Pr}^{\mathrm{t}}$ is the turbulent Prandtl number, $S c$ is the Schmidt number, $N_{\mathrm{e}}, N_{\mathrm{i}}$ 
Table 1. Gravity wave parameters estimated for the summer of 2010-2011 over Wasa. The vertical wavenumbers and the orientations of semi-major axes of the ellipses are estimated for two time intervals: 30 December 2010 at 19:30-21:15 UT and 11-12 January 2011 at 18:45-02:30 UT.

\begin{tabular}{|c|c|c|c|c|}
\hline \multirow[b]{2}{*}{$f\left(\operatorname{rad~s}^{-1}\right)$} & \multicolumn{2}{|c|}{30 December 2010} & \multicolumn{2}{|c|}{ 11-12 January 2011} \\
\hline & $-1.40 \times 10^{-4}$ & $-1.40 \times 10^{-4}$ & $-1.40 \times 10^{-4}$ & $-1.40 \times 10^{-4}$ \\
\hline$\theta$ (+ northward of east - southward of east) & $7^{\circ}$ & $7^{\circ}$ & $-16^{\circ}$ & $-16^{\circ}$ \\
\hline $2 \pi / \mathrm{m}(\mathrm{km})$ & -2.8 & -2.8 & -5.6 & -5.6 \\
\hline $2 \pi / \omega_{0}(\mathrm{~h})$ & 1.4 & 1.1 & 4.0 & 2.5 \\
\hline $2 \pi / \hat{\omega}(\mathrm{h})$ & 1.1 & 0.86 & 3.8 & 2.4 \\
\hline $2 \pi / \mathrm{k}(\mathrm{km})$ & -35.8 & -27.6 & -252.3 & -157.0 \\
\hline$v_{p h}\left(\mathrm{~m} \mathrm{~s}^{-1}\right)$ & -8.95 & -8.93 & -18.2 & -17.9 \\
\hline$v_{p z}\left(\mathrm{~m} \mathrm{~s}^{-1}\right)$ & -0.70 & -0.91 & -0.40 & -0.64 \\
\hline$v_{g h}\left(\mathrm{~m} \mathrm{~s}^{-1}\right)$ & -8.88 & -8.89 & -17.0 & -17.5 \\
\hline$v_{g z}\left(\mathrm{~m} \mathrm{~s}^{-1}\right)$ & 0.69 & 0.90 & 0.38 & 0.62 \\
\hline
\end{tabular}

and $N_{\mathrm{d}}$ are the electron, ion and dust/ice density, respectively, $\mathrm{d} N_{\mathrm{d}} / \mathrm{d} z$ is the dust density gradient, $Z_{\mathrm{d}}$ is the signed number of the dust elementary charge, $H_{\mathrm{n}}$ is the neutral scale height, $g$ is the gravitational acceleration. The values we use here for the above mentioned quantities are $k=2.28 \mathrm{rad} \mathrm{m}^{-1}$ for the MARA radar, $g=9.55 \mathrm{~m} \mathrm{~s}^{-2}$ considered as an appropriate value for the mesopause height.

We perform model calculations using the following mean atmospheric parameters as suggested by Varney et al. (2011): $\varepsilon=60 \mathrm{~mW} \mathrm{~kg}^{-1}, R i=0.81, \eta_{\mathrm{K}}=2.0 \mathrm{~m}, q=4.08, f_{\alpha}=2$, $P r^{\mathrm{t}}=1.0, S c=6506, Z_{\mathrm{d}}=-1$. For the quantities $\omega_{\mathrm{B}}, N_{\mathrm{e}}$, $N_{\mathrm{d}}, H_{\mathrm{n}}, v_{\mathrm{a}}, \mathrm{d} N_{\mathrm{d}} / \mathrm{d} z$ - we aim (and we are able) to estimate more accurate values. It should be noted that while Varney et al. (2011) used $q=4.08$ following Hill and Mitton (1998) and Hill et al. (1999), Rapp et al. (2008) and Li et al. (2010) have used $q=2$.

The ion-chemical model for the lower ionosphere from 50 to $110 \mathrm{~km}$ (the D-region) developed at the Polar Geophysical Institute is used to estimate the electron density profiles around the summer mesopause (Smirnova et al., 1988; Kirkwood and Osepian, 1995; Osepian et al., 2009; Barabash et al., 2012). The PGI model has been shown to reproduce electron density in the D-region adequately both under disturbed and quiet geophysical conditions. The recently updated version of the model yields electron density with a $1 \mathrm{~km}$ height resolution at any geographical point on the Earth's surface. The three profiles used in this study are shown in Fig. 6 (the reason for selection of these times is given below). It is seen that the model electron density profiles are rather smooth and are free of sharp gradients, which could potentially modulate PMSE profiles.

The next revised parameter is the neutral scale height. This parameter is important for the absolute value of PMSE reflectivity since the latter is inversely quadratically proportional to $H_{\mathrm{n}}$. As this quantity is a function of temperature, we have carefully considered the polar mesopause temperature using the NRLMSISE-00 neutral atmosphere model (Picone et al., 2002), with imposed temperature variations due to gravity waves of 5-10 K (Rapp et al., 2002). Thus, we have allowed the temperature to vary between 110 and $170 \mathrm{~K}$, that is the range of any possible realistic temperatures around the summer mesopause. Calculations demonstrate that the neutral scale height is changed between 3 and $5 \mathrm{~km}$ with a mean value of about $4 \mathrm{~km}$, which is applied in the present study. The neutral scale height of $1 \mathrm{~km}$ used by Varney et al. (2011) is too low, and should not be considered in any model studies related to the summer mesopause environment.

The next important parameter is the Brunt-Väisälä frequency. This parameter is a function of temperature gradient, and PMSE reflectivity is approximately a quadratic function of $\omega_{\mathrm{B}}$. Since the wind components are measured during PMSE occurrence, it is possible to estimate temperature perturbations due to gravity wave propagation. We use the relation (B3) derived by Muraoka et al. (1989) which relates temperature perturbations with vertical wind ones. An example of temperature perturbations and induced variations in the Brunt-Väisälä period $\left(T_{\mathrm{BV}}\right)$ is presented in Fig. 7. Here one can see typical temperature disturbances $(5-10 \mathrm{~K})$ produced by a medium-scale gravity wave with a period of about $3 \mathrm{~h}$, which induce variations in the $T_{\mathrm{BV}}$ between 2 and $8 \mathrm{~min}$. The reference (undisturbed) temperature profile was calculated based on the NRLMSISE-00 model.

The kinematic viscosity of air is an intrinsic property of the mixture of atmospheric gases and is controlled by their thermodynamical state. We follow the calculations of the viscosity described by Banks and Kockarts (1973). The kinematic viscosity of air can be estimated using the following relation:

$\nu_{\mathrm{a}}=A T^{0.69} / \rho$

with

$A=\sum A_{\mathrm{i}} n_{\mathrm{i}} / \sum n_{\mathrm{i}}$

where $A_{\mathrm{i}}$ are the numerical factors of the main atmospheric components $n_{\mathrm{i}}$ in the upper atmosphere (see Banks and Kockarts, 1973), $\rho$ is the atmospheric density taken from the 


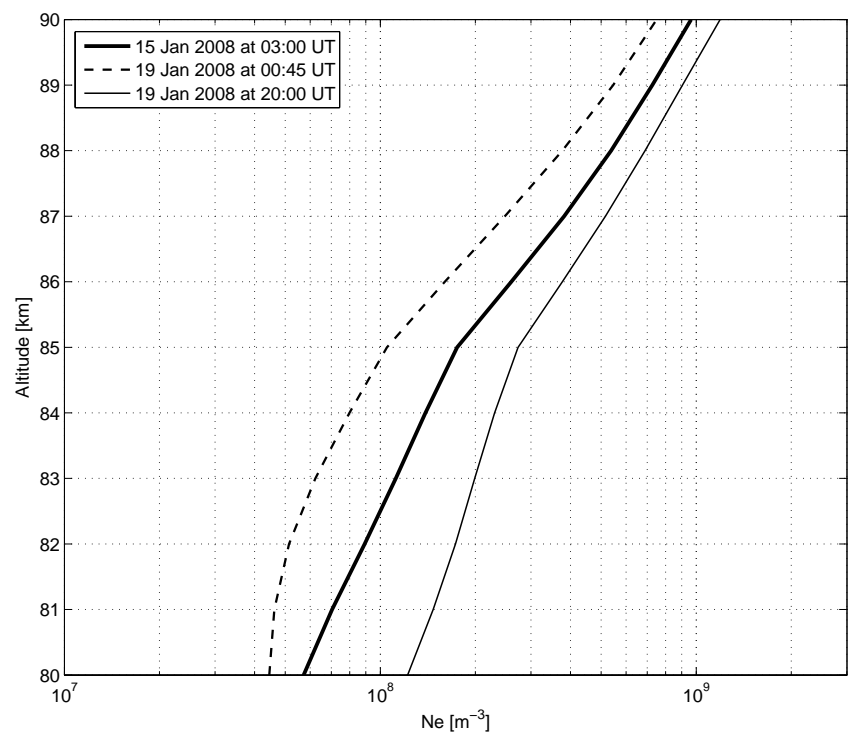

Fig. 6. Modeled electron density profiles for the three cases analyzed: 15 January 2008 at 03:00 UT (thick line), 19 January 2008 at 00:45 UT (dashed line) and 19 January 2008 at 20:00 UT (thin line).
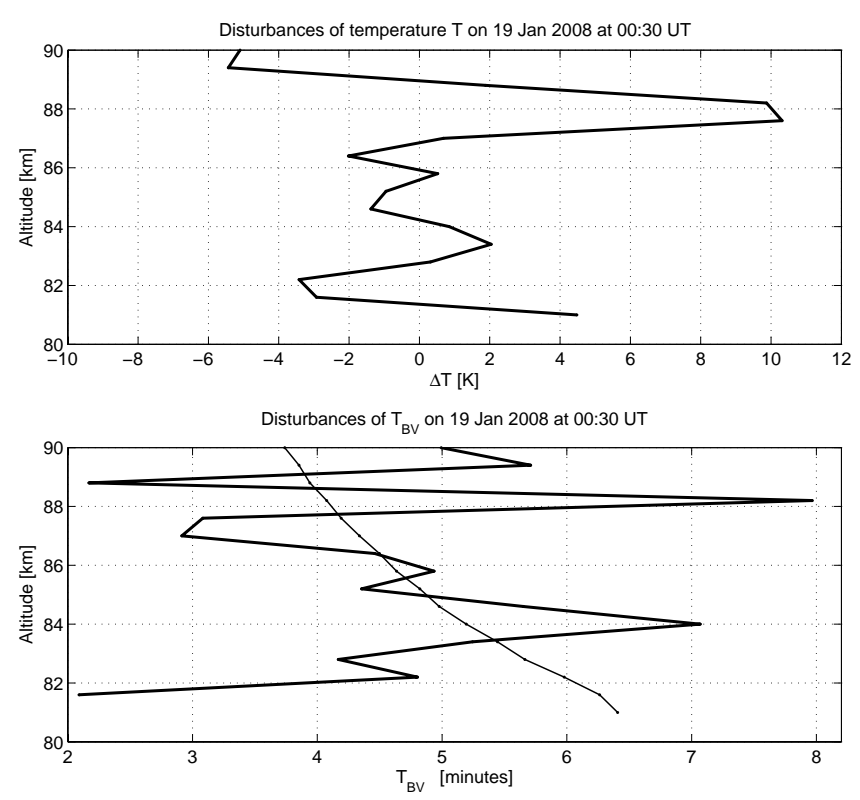

Fig. 7. Upper panel: temperature disturbances due to propagating gravity wave on 19 January at 00:30 UT. Lower panel: Induced disturbances in the Brunt-Väisälä period (thick line); the thin line is the undisturbed $T_{\mathrm{BV}}$.

NRLMSISE-00 model as a synoptic density. We use realistic temperature profiles, i.e. the synoptic temperatures from the NRLMSISE-00 model combined with temperature variations induced by gravity waves. The calculated profiles for the kinematic viscosity are illustrated in Fig. 8. It is seen that the viscosity slowly increases from 0.5 to $2 \mathrm{~m}^{2} \mathrm{~s}^{-1}$ in the height range $81-88 \mathrm{~km}$ and these values are close to the

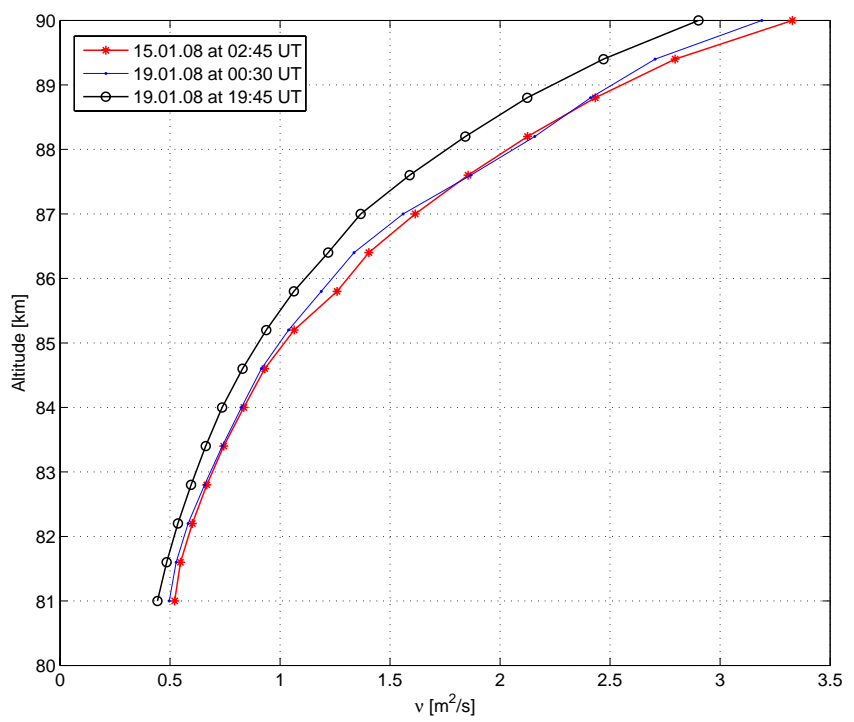

Fig. 8. Profiles of the kinematic viscosity of air calculated for three cases: on 15 January 2008 at 02:45 UT (red line), 19 January 2008 at 00:30 UT (blue line) and 19 January 2008 at 19:45 UT (black line).

mean value of $1 \mathrm{~m}^{2} \mathrm{~s}^{-1}$ used by Varney et al. (2011) in modeling the PMSE reflectivity. Note that $v_{\mathrm{a}}$ has a weak dependence on the temperature, and since $\eta(k) \propto \sqrt{\nu_{\mathrm{a}}}$ in the small $k$ limit (as valid for MARA), small variations in $v_{\text {a }}$ produce a small effect on the variability in the PMSE reflectivity. Nevertheless, we use our wave-perturbed model profiles of the viscosity of air to model the reflectivity as precisely as possible.

The turbulent energy dissipation rate is required to be correctly estimated and we can do this using a procedure of estimating the correlation life time $\left(T_{0.5}\right)$ of the diffraction pattern of the radar echo. The $T_{0.5}$ quantity is estimated with full correlation analysis (FCA), and it is the fading time of the structure in the reference frame of the mean background wind. It can be correctly estimated only at times when the signal-to-noise ratio (SNR) is greater than unity. Then the correlation time is unambiguously converted to an estimation of a turbulent root mean square velocity $\left(V_{\mathrm{fca}}\right)$ :

$V_{\mathrm{fca}}=\frac{\lambda \sqrt{2 \ln 2}}{4 \pi \cdot T_{0.5}}$

where is $\lambda$ is the radar wavelength. The $T_{0.5}$ quantity has an advantage over spectral width estimation since it removes the influence of horizontal winds on spectral width (Holdsworth et al., 2001; Satheesan and Kirkwood, 2010). Then the energy dissipation rate can be estimated as follows (Hocking, 1985):

$\varepsilon=0.4 \cdot V_{\mathrm{fca}}^{2} \cdot \omega_{\mathrm{B}}$

Note that the constant 0.4 is only approximately known. For example, Wilson (2004) used a constant equal to 0.47 in 


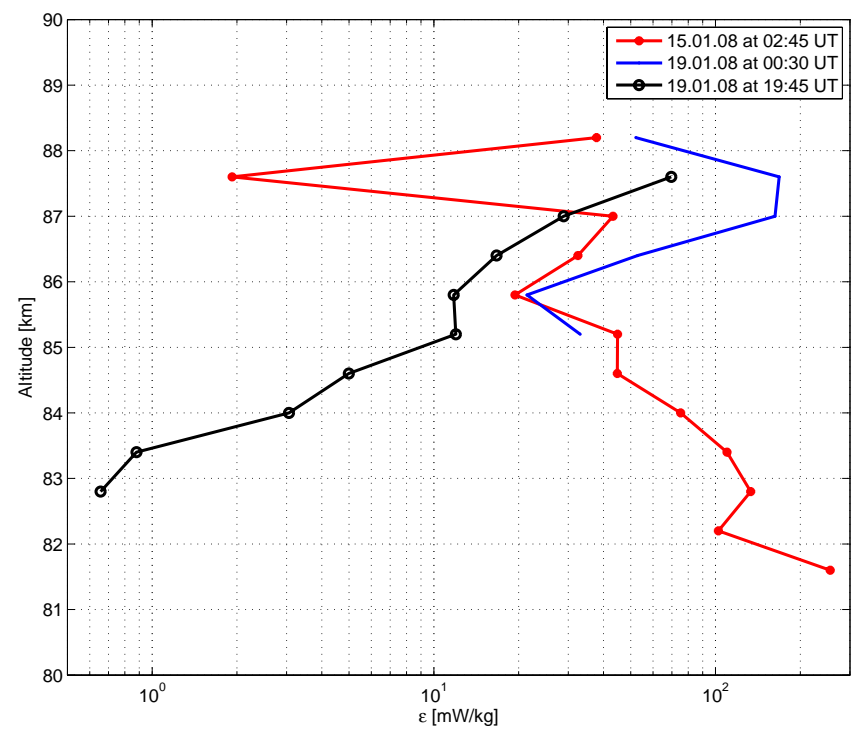

Fig. 9. Turbulent energy dissipation rate calculated on 15 January 2008 at 02:45 UT (red line), 19 January 2008 at 00:30 UT (blue line) and 19 January 2008 at 19:45 UT (black line).

this expression. Note that PMSE reflectivity depends on $\varepsilon$ as $\eta(k) \propto \sqrt{\varepsilon}$ in the small $k$ limit. If the energy dissipation rates typically vary from 30 to $300 \mathrm{~mW} \mathrm{~kg}^{-1}$ in the mesosphere (Rapp et al., 2008), then uncertainty due to $\varepsilon$ can be a factor of 3 or even more. So it is worth estimating the turbulent energy dissipation rate as precisely as possible, and three profiles of this quantity is shown in Fig. 9. It is seen that the turbulent energy dissipation rate varies differently and in a broad range for three cases: between 2 and $250 \mathrm{~mW} \mathrm{~kg}^{-1}$ on 15 January 2008 at $02: 45 \mathrm{UT}$, from 20 to $170 \mathrm{~mW} \mathrm{~kg}^{-1}$ on 19 January 2008 at 19:45 UT, whereas on 19 January 2008 at 00:30 UT it varies from 0.6 to $70 \mathrm{~mW} \mathrm{~kg}^{-1}$.

Theoretically, since we have wind measurements, it is possible to estimate another important turbulent parameter, the gradient Richardson number:

$R i=\omega_{\mathrm{B}}^{2} /\left((\mathrm{d} u / \mathrm{d} z)^{2}+(\mathrm{d} v / \mathrm{d} z)^{2}\right)$

where $\mathrm{d} u / \mathrm{d} z$ and $\mathrm{d} v / \mathrm{d} z$ are the vertical gradients of the horizontal components of wind velocity. But in reality, the uncertainties in the mesopause winds estimated by the radar are considerable, producing huge variance in the derivatives of the horizontal components. And hence, the uncertainty of estimating the Richardson number is the same order of magnitude as its average value. Thus, direct estimation of the gradient Richardson number from horizontal wind components does provide any reliable information for estimating the level of the turbulent state of the medium around the summer mesopause. Since the PMSE reflectivity is proportional to the Richardson number, this provides great uncertainties in modeling. Some sophisticated techniques, based on wind measurements, should be developed for estimating the gra-

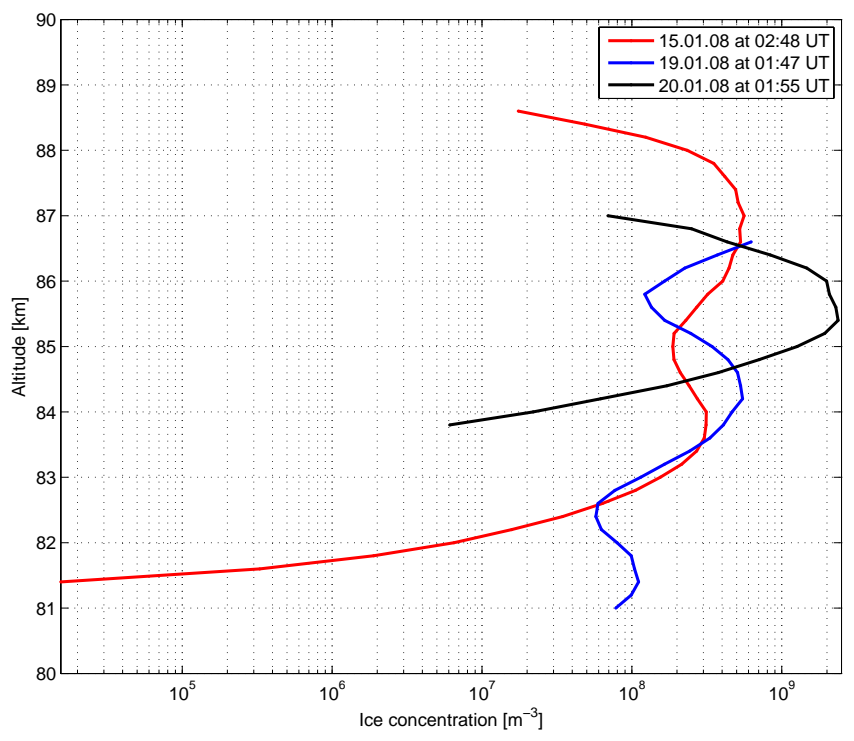

Fig. 10. Three profiles on the ice number density used for the analysis. Measurements are made with the SOFIE instrument on 15 January 2008 (red line), 19 January 2008 (blue line) and 20 January 2008 (green line).

dient Richardson number, but it is out of the scopes of the present paper. That is why we use the fixed Richardson number of 0.81 as was proposed in the model study by Varney et al. (2011).

The two final important quantities to be estimated adequately are the number density of ice particles and its height gradient. Nowadays there are available regular measurements of parameters of ice particles in the polar summer mesopause performed by the SOFIE instrument onboard the AIM satellite. A description of the SOFIE instrument, identification of mesospheric ice clouds, and the overview of the AIM mission can be found in Gordley et al. (2009), Hervig et al. (2009), and Russell et al. (2009), respectively. We have managed to find three profiles of the ice number density: on 15 January 2008 at 02:48 UT, 19 January 2008 at 01:47 UT and on 20 January at 01:55 UT, which are relatively close in geographical proximity to Wasa. These profiles are illustrated in Fig. 10. In fact, these profiles are good examples demonstrating the variety of the ice number density at different heights: low, medium and high concentrations with modulation in height. These values as well as their height gradients were utilized to calculate three theoretical profiles of PMSE reflectivity.

Now it is possible to model PMSE reflectivity and to investigate the significance of each variable component in PMSE variability. The theoretical profiles along with experimental ones of PMSE reflectivity are presented in Figs. 11-13. For the measured reflectivities, the error bars are shown as the standard deviation for a $15 \mathrm{~min}$ time interval. These represent relative uncertainties. The absolute uncertainty for volume reflectivities at MARA is estimated to be $20 \%$ (see 


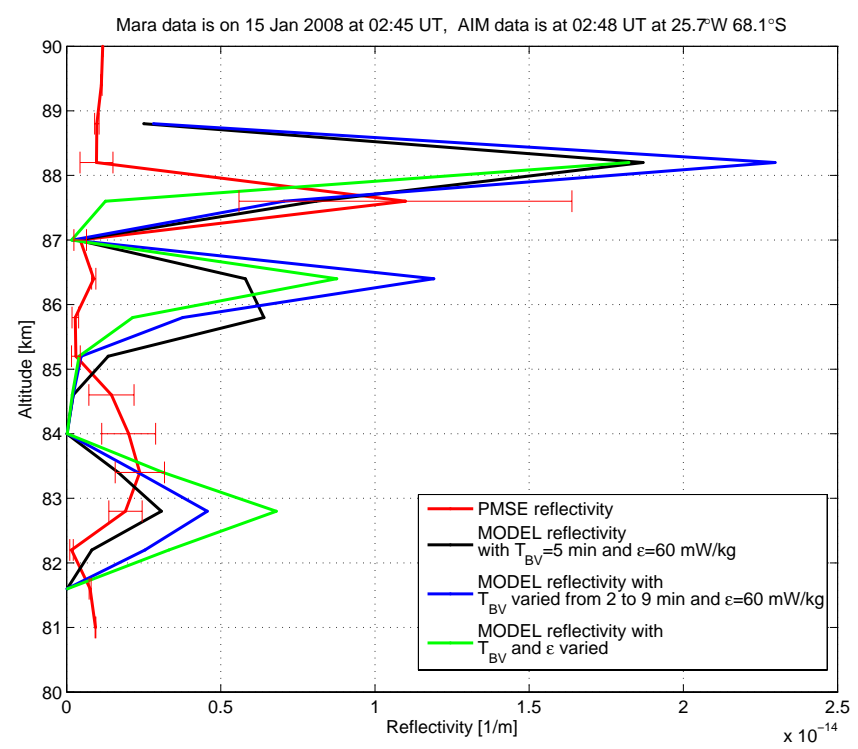

Fig. 11. Comparison between model (black, blue and green lines) and experimental profile of PMSE reflectivity (red line). The black line is for $T_{\mathrm{BV}}$ equal to $5 \mathrm{~min}$ with the fixed turbulent dissipation rate $\varepsilon=60 \mathrm{~mW} \mathrm{~kg}^{-1}$. The blue line is for varied $T_{\mathrm{BV}}$ changing from 2 to $9 \mathrm{~min}$ and $\varepsilon=60 \mathrm{~mW} \mathrm{~kg}^{-1}$. The green line is for varied $T_{\mathrm{BV}}$ and $\varepsilon$ with height. The error bar for the measured PMSE reflectivity is the standard deviation for $15 \mathrm{~min}$.

Kirkwood et al., 2010b). As the measurements of the ice number density were not made exactly in the same volume with PMSE, we have selected experimental PMSE profiles which are close in time to the ice measurements and have similar height behavior to the theoretical profiles of PMSE reflectivity.

Figure 11 shows an interesting double layer of measured PMSE with two peaks at $83-84 \mathrm{~km}$ and at $87.5 \mathrm{~km}$. The model profile (black line) was calculated under assuming a fixed value of the Brunt-Väisälä period of $5 \mathrm{~min}$, fixed $R i=0.81$ and $\varepsilon=60 \mathrm{~mW} \mathrm{~kg}^{-1}$ representing moderate level of turbulence, that is the same values used in modeling by Varney et al. (2011). One can see that the uppermost model peak is $600 \mathrm{~m}$ higher than the experimental one, and the model reflectivity exceeds the measured value by 1.7 times. The second modeled peak at $86 \mathrm{~km}$ altitude is not seen in the experimental profile. It could be that little active turbulence is present at this altitude relative to the layers above and below. However, moderate values of the turbulent energy dissipation rate from 20 to $45 \mathrm{~mW} \mathrm{~kg}^{-1}$ between 85 and $87 \mathrm{~km}$ (see Fig. 9) do not support this explanation. Note that turbulence has its smallest level $\left(\varepsilon=2 \mathrm{~mW} \mathrm{~kg}^{-1}\right)$ inside the main peak at $87.6 \mathrm{~km}$. The lowermost model peak around $83 \mathrm{~km}$ is close to the experimental one both in altitude and magnitude. Variations in $T_{\mathrm{BV}}$ (from 2 to $9 \mathrm{~min}$ ) modulate all the three model peaks and lead to an increase in magnitude of all three modeled peaks due to the increase in $T_{\mathrm{BV}}$ of $9,6,7$ and $5.5 \mathrm{~min}$ at the particular heights at $82.2,82.8,86.4$ and $88.2 \mathrm{~km}$, respec-

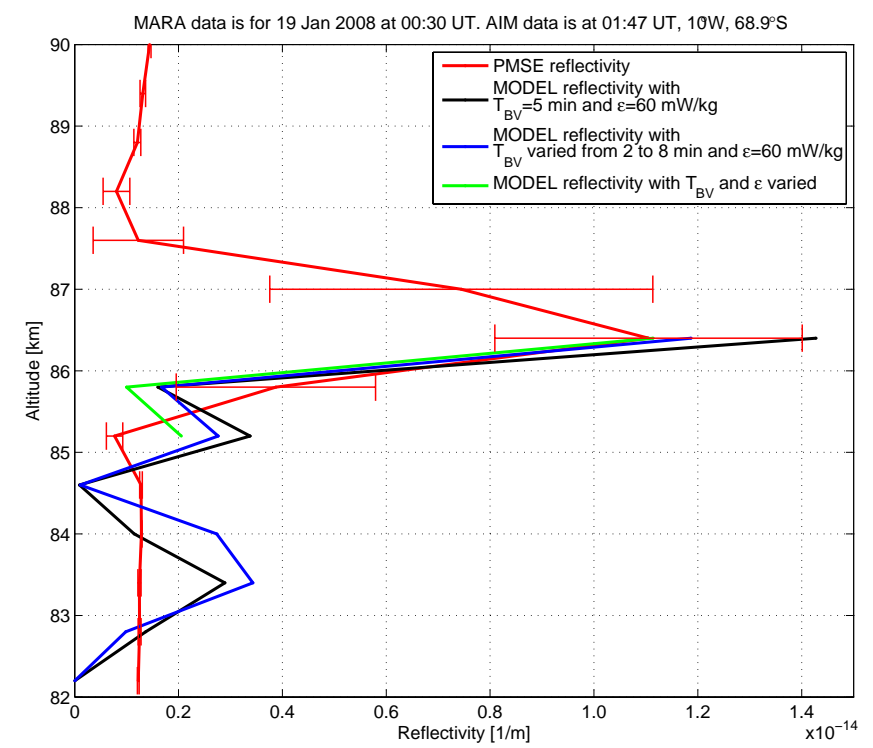

Fig. 12. Comparison between model (black, blue and green lines) and experimental profile of PMSE reflectivity (red line). The black line is for $T_{\mathrm{BV}}$ equal to $5 \mathrm{~min}$ with the fixed turbulent dissipation rate $\varepsilon=60 \mathrm{~mW} \mathrm{~kg}^{-1}$. The blue line is for varied $T_{\mathrm{BV}}$ changing from 2 to $8 \mathrm{~min}$ and $\varepsilon=60 \mathrm{~mW} \mathrm{~kg}^{-1}$. The green line is for varied $T_{\mathrm{BV}}$ and $\varepsilon$ with height. The error bar for the measured PMSE reflectivity is the standard deviation for $15 \mathrm{~min}$.

tively. Note that the buoyancy perturbed value of the second model peak at $86.4 \mathrm{~km}$ is increased about twice due to the increased $T_{\mathrm{BV}}$ value up to $7 \mathrm{~min}$. When variations in $\varepsilon$ are taken into account (green line), it produces noticeable variations in the lowermost, middle and uppermost model peaks of $50 \%, 27 \%$ and $20 \%$, respectively. Although the times of taking measurements of PMSE and ice profile are nearly the same, the distance between Wasa and the measured ice density profile is rather large and equal to $712 \mathrm{~km}$, thus the actual ice number density inside the PMSE layer was likely different, and the model PMSE layer at $86 \mathrm{~km}$ may not have been present in the actual PMSE layer above Wasa. Nevertheless, we consider this example demonstrates rather good agreement of the order of magnitude between the model and experimental PMSE reflectivity.

Figure 12 illustrates a single experimental PMSE peak at $86.5 \mathrm{~km}$ on 19 January 2008 at 00:30 UT (red line). The theoretical PMSE profile shows a good agreement both for absolute value and for variations in height (black line), with the model peak value being by $27 \%$ greater than the observation. Taking into account changes in the Brunt-Väisälä period (blue line), the model peak is less by $17 \%$ than those for $T_{\mathrm{BV}}$ equal to $5 \mathrm{~min}$, and is very close to the experimental PMSE value (by $8 \%$ greater) due to $T_{\mathrm{BV}}$ decreased to $4.5 \mathrm{~min}$ (see Fig. 7). At this particular height, variation in $T_{\mathrm{BV}}$ competes and compensates the increased ice number density (see Fig. 10). If $\varepsilon$ is allowed to vary with height, then the model peak perfectly matches the experimental, with the measured 


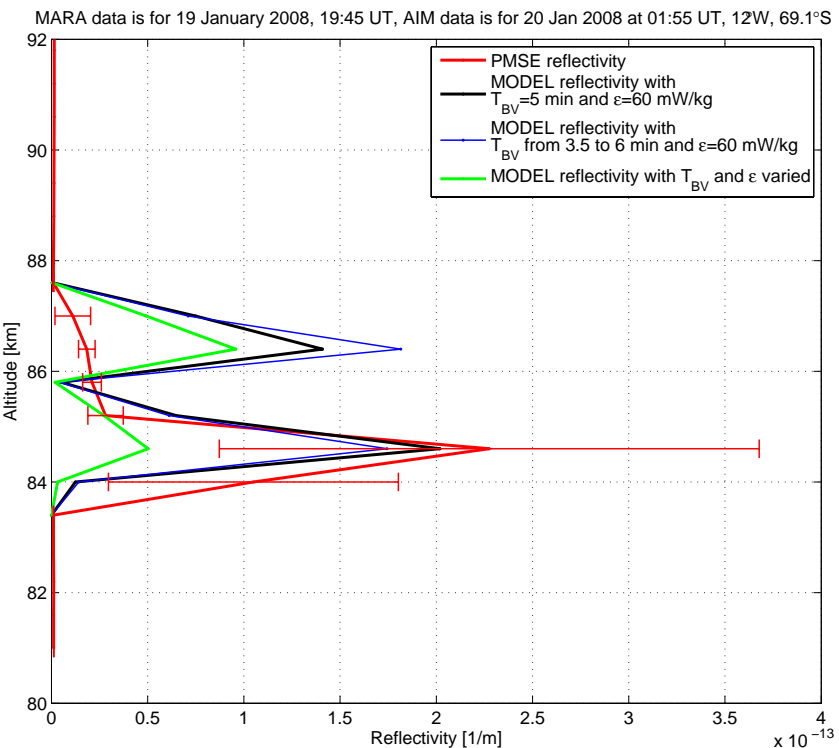

Fig. 13. Comparison between model (black, blue and lines) and experimental profile of PMSE reflectivity (red line). The black line is for $T_{\mathrm{BV}}$ equal to $5 \mathrm{~min}$ with the fixed turbulent dissipation rate $\varepsilon=60 \mathrm{~mW} \mathrm{~kg}^{-1}$. The blue line is for varied $T_{\mathrm{BV}}$ changing from 3.5 to $6 \mathrm{~min}$ and $\varepsilon=60 \mathrm{~mW} \mathrm{~kg}^{-1}$. The green line is for varied $T_{\mathrm{BV}}$ and $\varepsilon$ with height. The error bar for the measured PMSE reflectivity is the standard deviation for $15 \mathrm{~min}$.

$\varepsilon$ value equal to $53 \mathrm{~mW} \mathrm{~kg}^{-1}$ that is close to the fixed value of $60 \mathrm{~mW} \mathrm{~kg}^{-1}$. Note that only three model points of the green line are available for comparison with the measured profile, since, from the one hand, the $\varepsilon$ values are reliably estimated only between 85.2 and $88.2 \mathrm{~km}$ where SNR is greater than unity, and on the other hand, there are no measurements of the ice number density above $86.7 \mathrm{~km}$ for this case. The difference in the geographical positions of the measured ice profile and the actual location of PMSE is rather large, about $480 \mathrm{~km}$ for this case. This can explain the fact that two lower peaks are clearly seen in the model PMSE profile, but are absent in the experimental data. In spite of this spatial difference, we conclude that the model provides a very good agreement between the theoretical and experimental PMSE profile for this case. Note that this event was also considered by Kirkwood et al. (2010a) and the authors have demonstrated similar height-time behavior between ice mass density and PMSE volume reflectivity.

Figure 13 demonstrates the third comparison example between model and experimental PMSE, with the greatest values of the ice number density reaching a maximum of $2370 \mathrm{~cm}^{-3}$ at about $85.5 \mathrm{~km}$ (see Fig. 10). The most important, for this case, is that the ice density gradient reaches its maximum value $\left(1.7 \times 10^{6} \mathrm{~m}^{-4}\right)$ at $84.6 \mathrm{~km}$ altitude. Such large values result in high PMSE reflectivity, attaining $2.3 \times$ $10^{-13} \mathrm{~m}^{-1}$ (red line). Here we can see a good agreement between the model and experimental peak at $84.6 \mathrm{~km}$ both in the absolute value and height variations, with the model peak being less by $11 \%$. However, a secondary peak at $86.5 \mathrm{~km}$ is observed in the model data, which is absent in the experimental profile. The buoyancy period changes to a lesser extent, from 3.5 to $6 \mathrm{~min}$, within the height range from 82 to $90 \mathrm{~km}$, due to smaller temperature wave variations at this particular time, and the change in the buoyancy period equal to 4.5 min produces a small deviation from the nominal value of $5 \mathrm{~min}$ at the height of the PMSE maximum. This case is characterized by rather small and medium values of the turbulent energy dissipation rate gradually increasing from 0.65 to $70 \mathrm{~mW} \mathrm{~kg}^{-1}$. If $\varepsilon$ is allowed to vary with height (green line), then the model PMSE value is by $78 \%$ less than the measured one at the main peak at $84.6 \mathrm{~km}$, because of the small value $\varepsilon=5 \mathrm{~mW} \mathrm{~kg}^{-1}$. Since no active turbulence is indicated by the measurements within this strong and thick PMSE layer, except in the uppermost part between 87.0 and $87.6 \mathrm{~km}$, the ice number density and its variations with height should control the PMSE reflectivity in this particular case. Indeed, the greatest values reached by the ice number density and the ice density gradient make it possible to produce such large values in PMSE reflectivity. It is also possible that fossil turbulence might be responsible for the observed high level of PMSE reflectivity even in case if active turbulence is ended. Since radar reflectivity exponentially decays with the ambipolar diffusion coefficient, fossilized irregularities at VHF wavelengths can survive for a long time from $20 \mathrm{~min}$ to several hours (Rapp and Lübken, 2003), and those turbulent irregularities could be present at around $84-85 \mathrm{~km}$ and could be responsible for high values of PMSE reflectivity at $84.6 \mathrm{~km}$ seen in Fig. 13, even if the actual turbulent process has ended. It is important to note that the PMSE profile and ice density profile are not for the same time (time difference is about $6 \mathrm{~h}$ ) since PMSE had almost disappeared during the time of the AIM measurements at the closest position to Wasa, which is close to local midnight with very low electron densities. We selected this PMSE profile to demonstrate a good agreement between the model and experimental profile for high values of PMSE reflectivity and high values of the ice number density and its gradient. It might be readily possible that a similar ice profile was observed over Wasa at the moment of PMSE measurements on 19 January 2008 at 19:45 UT. On the other hand, the difference in the ice concentration might explain the discrepancy between the model and measurement values at the secondary peak at $86.4 \mathrm{~km}$. Probably, the actual ice number density and its gradient at $86.4 \mathrm{~km}$ above Wasa were smaller than those measured by AIM.

It is worth considering how the Schmidt number influences the reflectivity. We have done additional calculations with varying Schmidt numbers in a wide range from 500 to 6506 (large part of this range was considered by Rapp et al., 2008), and have found that PMSE reflectivities change by $15 \%$ only, i.e. within the statistical confidence interval for PMSE 
measurements. Thus, PMSE reflectivity has a very weak dependence on the Schmidt number at VHF wavelengths.

\section{Discussion}

It has been demonstrated in a case study of gravity wave excitation and propagation over Wasa (Arnault and Kirkwood, 2012) that mountain waves are excited over the nearby mountains and are able to propagate up to the lower stratosphere, where they break, exciting a cascade (secondary waves) of inertial-gravity waves with wavelengths between 15 and $40 \mathrm{~km}$. Theoretical studies by Fritts et al. (2009) supports this picture showing that wave breaking and wave-wave interactions may generate secondary waves. This partly coincides with the major wavelengths of medium scales (28 and $36 \mathrm{~km}$ ) obtained in the present study for the mesopause. We speculate now that inertial-gravity waves observed in the summer polar mesopause over Wasa might have a stratospheric source, where prevailing zonal winds dominate, thus fostering the excitation of gravity waves on average in the east-west direction, which we have found under this research. Further comprehensive researches on the gravity wave activity in the stratosphere-mesosphere are needed to resolve characteristic sources of inertial-gravity waves seen in the polar summer mesopause over Antarctica.

Pautet et al. (2011) have analyzed 30 cases of short-period gravity waves in NLC of the Northern Hemisphere at 60$65^{\circ} \mathrm{N}$ and have revealed that the majority of this type of wave has horizontal wavelengths in the range of $20-30 \mathrm{~km}$ with a mean value of about $25 \mathrm{~km}$. Also, it is interesting to note the study of the climatology of short-period gravity waves in the mesosphere over Antarctica at Halley Station at $76^{\circ} \mathrm{S}$ (Nielsen et al., 2009). The authors have treated the airglow data for the two winter seasons in 2000 and 2001 and estimated that the majority of gravity waves have horizontal wavelengths in the range of $15-40 \mathrm{~km}$ with a mean value of $26 \mathrm{~km}$. This result was obtained with an all-sky airglow imager, which is a completely different technique from the one utilized in the present study. However, our result that the most powerful gravity waves have a horizontal wavelength of $28 \mathrm{~km}$ for the Antarctic summer mesopause perfectly fits the mean value obtained by Nielsen et al. (2009). Of course, it might be just a coincidence but rather it is likely a common characterization of the gravity wave activity both in summer and winter seasons over the Antarctic, and moreover, gravity waves with horizontal wavelengths of $25-40 \mathrm{~km}$ seem to be common for the mesopause of both hemispheres. This topic requires further considerations using PMSE data sets for other seasons, which we plan to perform in future.

Currently, large-scale gravity waves are also extensively studied with satellite measurements. Chandran et al. (2010) have used images of polar mesospheric clouds made with the CIPS instrument onboard the AIM satellite and have found the distributions of horizontal wavelengths of gravity waves having a peak at $250-300 \mathrm{~km}$; the study included both hemispheres between 70 and $80^{\circ}$ for the summer seasons of 2007 and 2008. Our estimation of horizontal wavelength equal to $252 \mathrm{~km}$ perfectly fits this result. Meanwhile, Taylor et al. (2011) have found that the distribution of horizontal wavelength had a strong peak at the shortest wavelengths, with over $75 \%$ of the gravity wave events having wavelengths less than $100 \mathrm{~km}$. The authors estimated the direction of motion of the waves was predominantly zonal, which is in agreement with the results of the present study. The authors have utilized the CIPS data set for the July 2007 period and identified over 450 quasi-monochromatic wave events. It is interesting to note that previously Chandran et al. (2009) have obtained similar results, i.e. most of the waves had wavelengths less than $100 \mathrm{~km}$, but later Chandran et al. (2010) have argued that it was due to the visual detection method of wave patterns in CIPS images and "...Visual analysis of CIPS images is biased toward the smaller scale structures... The visual analysis is biased towards picking wave events in individual clouds and very often the larger scale structures will be missed". So it seems that retrieving of gravity wave parameters from satellite data is a function of the technique applied.

Study of planetary waves with PMSE time series is also a fruitful topic for current investigations of the dynamic features of the polar summer mesopause. The 2-, 5- and 10-15-days planetary waves have been studied with PMSE measurements in a number of publications (Kirkwood and Réchou, 1998; Klekociuk et al., 2008; Morris et al., 2009). The quasi 2-day planetary wave is also a well known atmospheric periodic process in the upper atmosphere (Muller and Nelson, 1978; Rodgers and Prata, 1981; Salby, 1981; Pogoreltsev, 1999). The 2-day planetary wave also was found to be a significant wave disturbance in noctilucent clouds (Dalin et al., 2008).

It is important to note that Morris et al. (2009) have found the 2-day wave being a dominating planetary wave oscillation above Davis station $\left(69^{\circ} \mathrm{S}\right)$ during the course of four consecutive austral summer seasons for 2004-2005, 20052006, 2006-2007 and 2007-2008. The period of the quasi 2-day wave has been shown to vary between 1.7 to 2.3 days from year to year. Moreover, the authors have found a type of planetary wave (among others) propagating eastward with zonal wavenumber equal to 2 and having a period of 2.2 days, which is close to the period of 2.3 days we have found. On the other hand, it is well known that the 5-day planetary wave has a strong seasonal and inter-annual variability in the upper stratosphere, based on long data sets for 1992-2001 (Fedulina et al., 2004). We have also found periodic signals at about 2 and 5 days in PMSE over Wasa, the latter with statistical significance below the $95 \%$ confidence level. However, this 5-day oscillation is clearly present in the power spectrum indicating that the 5-day wave magnitude was not so strong compared to the 2-day wave magnitude for the 2010/2011 austral summer. All these findings are in good agreement 
with the all above mentioned features for the 2-day and 5day planetary wave activity.

We cannot test the alternative model proposed by Rapp et al. (2008) since their model is a strong function of the electron number density and electron density gradient, which are not available, on a regular base, as in-situ measurements inside PMSE layer. It was point out by Varney et al. (2011) that "The expression for reflectivity corresponding to this solution, i.e. Eq. (44), is identical to that derived by Rapp et al. (2008) except the leading term involving the electron density and density gradient has been replaced by a term involving the dust density and density gradient and the relative densities of electrons and dust". On the other hand, nowadays there are continuous ice measurements around the polar summer mesopause provided by the SOFIE instrument, and it is a good opportunity to check the correctness of the model proposed by Varney et al. (2011) since there are regular measurements of PMSE.

We have carefully inspected the actual values of the three terms entering the $\tilde{M}$-term (see Eq. 9) and have found that these terms are of the same order of magnitude if the dust density has low and moderate values. It means that the three terms compete with each other when producing PMSE reflectivity of low and moderate magnitudes. In addition, the first term responsible for PMSE reflectivity (Eq. 7) is inversely quadratically proportional to the Brunt-Väisälä frequency. Thus, the ice number density, its gradient and the ice gradient due to variations in the buoyancy frequency all these factors are of importance for PMSE formation and variability.

Note that Gibson-Wilde et al. (2000) have simulated a turbulent layer generated by a Kelvin-Helmholtz instability which has demonstrated formation of two strong layers in the radar backscattered power, separated by $1.2 \mathrm{~km}$ in height, with the buoyancy period varying from 4 to $15 \mathrm{~min}$ inside the turbulent layer. The authors pointed out that the buoyancy frequency is spatially and temporally variable, and highly dependent on the resolution of any temperature measurements available. In general, if considering a turbulent scatter from the atmosphere, the radar reflectivity depends both on the three-dimensional power spectrum of fluctuations of the refractive index $\left(\Phi_{n}(k)\right)$ and the gradient of the mean dust density $(\tilde{M})$ (Booker, 1956; Hocking, 1985; Rapp et al., 2008; Varney et al, 2011). In turn, the last two quantities depend on the static stability of air parcel, that is $\Phi_{n}(k) \propto \omega_{\mathrm{B}}^{-2}$ and $\tilde{M} \propto \omega_{\mathrm{B}}^{2}$ (in case of small dust number density and its height gradient), with reflectivity $\eta(k) \propto \tilde{M}^{2}$.

In general, we have found a good agreement between model and experimental PMSE volume reflectivity both in the magnitude and height variations, when neutral atmospheric parameters are close to their mean values. Considering variability due to variations in $\omega_{\mathrm{B}}^{2}$ due to waves, model PMSE ferlectivities can change by up to a factor 2 . If one considers actual variability of the turbulent energy dissipa- tion rate, then model PMSE reflectivities can significantly differ (by about 80\%) from the measured value. Special care should be given for estimating the Richardson number, which may vary significantly in height and time, which in turn might produce large deviations from measured PMSE values, since the reflectivity is proportional to Ri. Accordingly, it is required to develop a special technique to correctly estimate the derivatives of the horizontal wind components, which is not possible with the present measurements. At the same time, we have demonstrated that all major PMSE peaks are explained in terms of the ice number density and its height gradient. Smaller model peaks, which are not seen in the measured PMSE profiles, have been formed by the ice constituent measured by AIM at significant distances from Wasa, which probably have been different from those located in the mesopause directly above Wasa. Thus, the major role in PMSE formation and their variability should be given to the ice number density and its gradient. This is in line with the results obtained by Hervig et al. (2011) who have performed a detailed comparison of PMSE data measured with the ALOMAR wind (ALWIN) radar and the SOFIE ice particle data and demonstrated a consistent relationship between PMSE reflectivity and ice concentration at all altitudes around the summer mesopause, and the authors concluded that "PMC and PMSE are different manifestations of the same ice layer".

\section{Conclusions}

1. For the first time, a detailed comparison between theoretical and experimental PMSE volume reflectivity, measured above Antarctica, has been made. It has been demonstrated that a new expression for PMSE reflectivity derived by Varney et al. (2011) is able to adequately describe PMSE profiles both in the magnitude and in height variations. The best agreement, within $30 \%$, is achieved when mean and fixed in height neutral atmospheric parameters are utilized. If profiles of the turbulent energy dissipation rate derived from data are considered, then model PMSE reflectivities might be significantly different (by $80 \%$ ) from those calculated with the fixed parameters. We have found that the most contribution to the formation and variability of the PMSE layer is explained in terms of the ice concentration and its height gradient, followed by the turbulent energy dissipation rate. Special care is required to estimate the Richardson number, which may vary by several orders of magnitude in time and space around the summer mesopause. When modeling, it is also importance to consider variations in the Brunt-Väisälä frequency due to upward propagating inertial-gravity waves. The inverse quantity of the last parameter (the buoyancy period) can vary from 2 to 9 min under actual atmospheric conditions, which can lead to deviations in 
PMSE reflectivity from those calculated for the nominal value of the buoyancy period (usually taken as $5 \mathrm{~min}$ for the summer mesopause) by about a factor of 2 .

2. We have comprehensively analyzed the wave activity in the Antarctic summer mesopause over Wasa based on PMSE measurements for December 2010-January 2011. Signatures of the 2- and 5-day planetary waves have been found in the power spectrum density of PMSE power, with the former being highly significant and more powerful. The strongest periodic oscillation in the whole power spectrum belongs to the diurnal solar tide; the semi-diurnal solar tide is a highly significant periodic process in the summer mesopause as well.

3. The inertial-gravity waves have been extensively studied by analyzing PMSE power and wind components. The strongest gravity waves have been observed at the periods of about $1,1.4,2.5$ and $4 \mathrm{~h}$ for the austral summer season of December 2010-January 2011. Two selected cases have demonstrated gravity waves having characteristic horizontal wavelengths of 28,36 , 157 and $252 \mathrm{~km}$, respectively. The gravity waves have propagated preferentially in the west-east direction over Wasa.

Acknowledgements. The paper benefited from constructive comments and suggestions made by reviewer R. H. Varney and one anonymous reviewer. Measurements with MARA were part of the SWEDARP and FINNARP expeditions to Queen Maud Land, Antarctica in 2007/2008 and 2010/2011. Funding for the MARA radar was provided by the Wallenberg Foundation, Sweden. The research has otherwise been supported by the Swedish Research Council (grants 621-2007-4812 and 621-2010-3218), with logistical support from Swedish Polar Research Secretariat and Finnish Academy of Science. Many thanks to the SOFIE/AIM team, AIM is funded by NASA's Small Explorers Program under contract NAS503132.

Topical Editor C. Jacobi thanks R. Varney and one anonymous referee for their help in evaluating this paper.

\section{References}

Arnault, J. and Kirkwood, S.: Dynamical influence of gravity waves generated by the Vestfjella Mountains in Antarctica: radar observations, fine-scale modeling and kinetic energy budget analysis, Tellus A, 64, 17261, doi:10.3402/tellusa.v64i0.17261, 2012.

Banks, P. M. and Kockarts, G.: Aeronomy, Part B, Academic Press, New York and London, 355 pp., 1973.

Barabash, V., Osepian, A., Dalin, P., Kirkwood, S., and Tereschenko, V.: Electron density profiles in the quiet lower ionosphere based on the results of modeling and experimental data, Ann. Geophys., accepted, 2012.

Booker, H. G.: A theory of scattering by non-isotropic irregularities with application to radar reflections from the aurora, J. Atmos. Terr. Phys., 8, 204-221, 1956.
Chandran, A., Rusch, D., Palo, S. E., Thomas, G. E., and Taylor, M.: Gravity wave observations from the Cloud Imaging and Particle Size (CIPS) Experiment on the AIM Spacecraft, J. Atmos. Sol.Terr. Phy., 71, 392-400, doi:10.1016/j.jastp.2008.09.041, 2009.

Chandran, A., Rusch, D. W., Merkel, A. W., Palo, S. E., Thomas, G. E., Taylor, M. J., Bailey, S. M., and Russell III, J. M.: Polar mesospheric cloud structures observed from the cloud imaging and particle size experiment on the Aeronomy of Ice in the Mesosphere spacecraft: atmospheric gravity waves as drivers for longitudinal variability in polar mesospheric cloud occurrence, J. Geophys. Res., 115, D13102, doi:10.1029/2009JD013185, 2010.

Cho, J. Y. N.: Inertio-gravity wave parameter estimation from crossspectral analysis, J. Geophys. Res., 100, 18727-18737, 1995.

Cho, J. Y. N. and Röttger, J.: An updated review of polar mesosphere summer echoes: observations, theory, and their relationship to noctilucent clouds and subvisible aerosols, J. Geophys. Res., 102, 2001-2020, 1997.

Dalin, P., Kirkwood, S., Moström, A., Stebel, K., Hoffmann, P., and Singer, W.: A case study of gravity waves in noctilucent clouds, Ann. Geophys., 22, 1875-1884, doi:10.5194/angeo-221875-2004, 2004.

Dalin, P., Pertsev, N., Zadorozhny, A., Connors, M., Schofield, I., Shelton, I., Zalcik, M., McEwan, T., McEachran, I., Frandsen, S., Hansen, O., Andersen, H., Sukhodoev, V., Perminov, V., and Romejko, V.: Ground-based observations of noctilucent clouds with a northern hemisphere network of automatic digital cameras, J. Atmos. Sol-Terr. Phy., 70, 1460-1472, doi:10.1016/j.jastp.2008.04.018, 2008.

Eckermann, S. D.: Hodographic analysis of gravity waves: relationships among Stokes parameters, rotary spectra and cross-spectral methods, J. Geophys. Res., 101, 19169-19174, 1996.

Eckermann, S. D. and Vincent, R. A.: Falling sphere observations of anisotropic gravity wave motions in the upper stratosphere over Australia, Pure Appl. Geophys., 130, 509-532, 1989.

Fedulina, I. N., Pogoreltsev, A. I., and Vaughan, G.: Seasonal, interannual and short-term variability of planetary waves in Met Office stratospheric assimilated fields, Q. J. Roy. Meteorol. Soc., 130, 2445-2458, 2004.

Fiedler, J., Baumgarten, G., and von Cossart, G.: Mean diurnal variations of noctilucent clouds during 7 years of lidar observations at ALOMAR, Ann. Geophys., 23, 1175-1181, doi:10.5194/angeo-23-1175-2005, 2005.

Fritts, D. C., Wang, L., Werne, J., Lund, T., and Wan, K.: Gravity wave instability dynamics at high Reynolds numbers. Part I: wave field evolution at large amplitudes and high frequencies, J. Atmos. Sci., 66, 1126-1148, doi:10.1175/2008JAS2726.1, 2009.

Gibson-Wilde, D., Werne, J., Fritts, D., and Hill, R.: Direct numerical simulation of VHF radar measurements of turbulence in the mesosphere, Radio Sci., 35, 783-798, 2000.

Gordley, L. L., Hervig, M. E., Fish, C., Russell, J. M., Bailey, S., Cook, J., Hansen, S., Shumway, A., Paxton, G., Deaver, L., Marshall, T., Burton, J., Magill, B., Brown, C., Thompson, E., and Kemp, J.: The solar occultation for ice experiment, J. Atmos. Sol.-Terr. Phy., 71, 300-315, doi:10.1016/j.jastp.2008.07.012, 2009.

Hervig, M. E., Gordley, L. L., Stevens, M., Russell, J. M., Bailey, S., and Baumgarten, G.: Interpretation of SOFIE PMC measurements: Cloud identification and derivation of mass density, particle shape, and particle size, J. Atmos. Sol.-Terr. Phy., 71, 
316-330, doi:10.1016/j.jastp.2008.07.009, 2009.

Hervig, M. E., Rapp, M., Latteck, R., and Gordley, L. L.: Observations of mesospheric ice particles from the ALWIN radar and SOFIE, J. Atmos. Sol.-Terr. Phy., 73, 2176-2183, doi:10.1016/j.jastp.2010.08.002, 2011.

Hill, R. J. and Mitton, K. A.: Turbulence-induced ionization fluctuations in the lower ionosphere, Tech. Report ERL 454-ETL 68, NOAA, 1998.

Hill, R. J., Gibson-Wilde, D. E., Werne, J. A., and Fritts, D. C.: Turbulence induced fluctuations in ionization and application to PMSE, Earth Planets Space, 51, 499-513, 1999.

Hocking, W. K.: Measurement of turbulent energy dissipation rates in the middle atmosphere by radar techniques: A review, Radio Sci., 20, 1403-1422, 1985.

Holdsworth, D. A., Vincent, R. A., and Reid, I. M.: Mesospheric turbulent velocity estimation using the Buckland Park MF radar, Ann. Geophys., 19, 1007-1017, doi:10.5194/angeo-19-10072001, 2001.

Kelley, M. C., Farley, D. T., and Röttger, J.: The effect of cluster ions on anomalous VHF backscatter from the summer polar mesopause, Geophys. Res. Lett., 14, 1031-1034, 1987.

Kirkwood, S. and Osepian, A.: Quantitative studies of energetic particle precipitation using incoherent scatter radar, J. Geomag. Geoelectr., 47, 783-799, 1995.

Kirkwood, S. and Réchou, A.: Planetary-wave modulation of PMSE, Geophys. Res. Lett., 25, 4509-4512, 1998.

Kirkwood, S., Wolf, I., Nilsson, H., Dalin, P., Mikhaylova, D., and Belova, E.: Polar mesosphere summer echoes at Wasa, Antarctica $\left(73^{\circ} \mathrm{S}\right)$ : first observations and comparison with $68^{\circ} \mathrm{N}$, Geophys. Res. Lett., 34, L15803, doi:10.1029/2007GL030516, 2007.

Kirkwood, S., Hervig, M., Belova, E., and Osepian, A.: Quantitative relation between PMSE and ice mass density, Ann. Geophys., 28, 1333-1343, doi:10.5194/angeo-28-1333-2010, 2010a.

Kirkwood, S., Belova, E., Satheesan, K., Narayana Rao, T., Rajendra Prasad, T., and Satheesh Kumar, S.: Fresnel scatter revisited - comparison of $50 \mathrm{MHz}$ radar and radiosondes in the Arctic, the Tropics and Antarctica, Ann. Geophys., 28, 1993-2005, doi:10.5194/angeo-28-1993-2010, 2010b.

Klekociuk, A. R., Morris, R. J., and Innis, J. L.: First Southern Hemisphere common-volume measurements of PMC and PMSE, Geophys. Res. Lett., 35, L24804, doi:10.1029/2008GL035988, 2008.

Li, Q., Rapp, M., Röttger, J., Latteck, R., Zecha, M., Strelnikova, I., Baumgarten, G., Hervig, M., Hall, C., and Tsutsumi, M.: Microphysical parameters of mesospheric ice clouds derived from calibrated observations of polar mesospheric summer echoes at Bragg wavelengths of $2.8 \mathrm{~m}$ and $30 \mathrm{~cm}$, J. Geophys. Res., 115, D00I13, doi:110.1029/2009JD012271, 2010.

Mann, M. E. and Lees, J. M.: Robust estimation of background noise and signal detection in climatic time series, Climatic Change, 33, 409-445, 1996.

Morris, R. J., Klekociuk, A. R., and Holdsworth, D. A.: Low latitude 2-day planetary wave impact on austral polar mesopause temperatures: revealed by a January diminution in PMSE above Davis, Antarctica, Geophys. Res. Lett., 36, L11807, doi:10.1029/2009GL037817, 2009.

Muller, H. G. and Nelson, L.: A travelling quasi 2-day wave in the meteor region, J. Atmos. Terr. Phys., 40, 761-766, 1978.
Muraoka, Y., Sugiyama, T., Sato, T., Tsuda, T., Fukao, S., and Kato, S.: Interpretation of layered structure in mesospheric VHF echoes induced by an inertia gravity wave, Radio Sci., 24, 393406, 1989.

Nielsen, K., Taylor, M. J., Hibbins, R. E., and Jarvis, M. J.: Climatology of short-period mesospheric gravity waves over Halley, Antarctica $\left(76^{\circ} \mathrm{S}, 27^{\circ} \mathrm{W}\right)$, J. Atmos. Sol.-Terr. Phy., 71, 9911000, doi:10.1016/j.jastp.2009.04.005, 2009.

Nilsson, H., Kirkwood, S., Morris, R. J., Latteck, R., Klekociuk, A. R., Murphy, D. J., Zecha, M., and Belova, E.: Simultaneous observations of Polar Mesosphere Summer Echoes at two different latitudes in Antarctica, Ann. Geophys., 26, 3783-3792, doi:10.5194/angeo-26-3783-2008, 2008.

Nussbaumer, V., Fricke, K.-H., Langer, M., Singer, W., and von Zahn, U.: First simultaneous and common volume observations of noctilucent clouds and polar mesosphere summer echoes by lidar and radar, J. Geophys. Res., 101, 19161-19167, 1996.

Osepian, A., Kirkwood, S., and Dalin, P.: The influence of ozone concentration on the lower ionosphere - modelling and measurements during the 29-30 October 2003 solar proton event, Ann. Geophys., 27, 577-589, doi:10.5194/angeo-27-577-2009, 2009.

Pautet, P.-D., Stegman, J., Wrasse, C. M., Nielsen, K., Takahashi, H., Taylor, M. J., Hoppel, K. W., and Eckermann, S. D.: Analysis of gravity waves structures visible in noctilucent cloud images, J. Atmos. Sol.-Terr. Phy., 73, 2082-2090, doi:10.1016/j.jastp.2010.06.001, 2011.

Percival, D. B. and Walden, A. T.: Spectral Analysis for Physical Applications: Multitaper and Conventional Univariate Techniques, Cambridge University Press, 1993.

Picone, J. M., Hedin, A. E., Drob, D. P., and Aikin, A. C.: NRLMSISE-00 empirical model of the atmosphere: statistical comparisons and scientific issues, J. Geophys. Res., 107, 1468, doi:10.1029/2002JA009430, 2002.

Pogoreltsev, A.: Simulation of planetary waves and their influence on the zonally averaged circulation in the middle atmosphere, Earth Planets Space, 51, 773-784, 1999.

Rapp, M. and Lübken, F.-J.: On the nature of PMSE: electron diffusion in the vicinity of charged particles revisited, J. Geophys. Res., 108, 8437, doi:10.1029/2002JD002857, 2003.

Rapp, M., Lübken, F.-J., Müllemann, A., Thomas, G. E., and Jensen, E. J.: Small scale temperature variations in the vicinity of NLC: experimental and model results, J. Geophys. Res., 107, 4392, doi:10.1029/2001JD001241, 2002.

Rapp, M., Strelnikova, I., Latteck, R., Hoffman, P., Hoppe, U.P., Häggström, I., and Rietveld, M.: Polar mesosphere summer echoes (PMSE) studied at Bragg wavelengths of $2.8 \mathrm{~m}, 67 \mathrm{~cm}$, and $16 \mathrm{~cm}$, J. Atmos. Sol.-Terr. Phy., 70, 947-961, 2008.

Rodgers, C. D. and Prata, A.: Evidence for a traveling 2-day wave in the middle atmosphere, J. Geophys. Res., 86, 9661-9664, 1981.

Russell, J. M., Bailey, S. M., Gordley, L. L., Rusch, D.W., Horányi, M., Hervig, M. E., Thomas, G. E., Randall, C. E., Siskind, D. E., Stevens, M. H., Summers, M. E., Taylor, M. J., Englert, C. R., Espy, P. J., McClintock, W. E., and Merkel, A. W.: The Aeronomy of Ice in the Mesosphere (AIM) mission: Overview and early science results, J. Atmos. Sol.-Terr. Phy., 71, 289-299, doi:10.1016/j.jastp.2008.08.011, 2009.

Salby, M. L.: Rossby normal modes in nonuniform background configurations. Part II: equinox and solstice conditions, J. Atmos. Sci., 38, 1827-1840, 1981. 
Satheesan, K. and Kirkwood, S.: Turbulence for different background conditions using fuzzy logic and clustering, Ann. Geophys., 28, 1475-1481, doi:10.5194/angeo-28-1475-2010, 2010.

Shettle, E. P., DeLand, M. T., Thomas, G. E., and Olivero, J. J.: Long term variations in the frequency of polar mesospheric clouds in the Northern Hemisphere from SBUV, Geophys. Res. Lett., 36, 2803-2806, doi:10.1029/2008GL036048, 2009.

Smirnova, M., Belova, E., Kirkwood, S., and Mitchell, N.: Polar mesosphere summer echoes with ESRAD, Kiruna, Sweden: Variations and trends over 1997-2008, J. Atmos. Sol.-Terr. Phy., 72, 435-447, doi:10.1016/j.jastp.2009.12.014, 2010.

Smirnova, N. V., Ogloblina, O. F., and Vlaskov, V. A.: Modelling of the lower ionosphere, Pure Appl. Geophys., 127, 353-379, 1988.

Taylor, M. J., Pautet, P.-D., Zhao, Y., Randall, C. E., Lumpe, J., Bailey, S. M., Carstens, J., Nielsen, K., Russell, J. M., and Stegman, J.: High-latitude gravity wave measurements in noctilucent clouds and polar mesospheric clouds, Aeronomy of the Earth's Atmosphere and Ionosphere, IAGA Special Sopron Book Series, V. 2, Part 1, 93-105, doi:10.1007/978-94-007-0326-1_7, 2011.
Varney, R. H., Kelley, M. C., Nicolls, M. J., Heinselman, C. J., and Collins, R. L.: The electron density dependence of polar mesospheric summer echoes, J. Atmos. Sol.-Terr. Phys., 73, 2153 2165, doi:10.1016/j.jastp.2010.07.020, 2011.

Vincent, R. A. and Fritts, D. C.: A climatology of gravity wave motions in the mesopause region at Adelaide, Australia, J. Atmos. Sci., 44, 748-760, 1987.

von Zahn, U. and Bremer, J.: Simultaneous and common-volume observations of noctilucent clouds and polar mesospheric summer echoes, Geophys. Res. Lett., 11, 1521-1524, 1999.

Wilson, R.: Turbulent diffusivity in the free atmosphere inferred from MST radar measurements: a review, Ann. Geophys., 22, 3869-3887, doi:10.5194/angeo-22-3869-2004, 2004. 